Indigenous children's connectedness to nature: the potential influence of culture, gender and exposure to a contaminated environment

W. Sedawi

Department of Science and Technology Education, Ben-Gurion University of the Negev, Beer-Sheva, Israel.

e-mail: wisams@post.bgu.ac.il

O. Ben Zvi Assaraf

Department of Science and Technology Education, Ben-Gurion University of the Negev, Beer-Sheva, Israel.

e-mail:ntorit@bgu.ac.il

M. J. Reiss

UCL Institute of Education, University College London, London, UK

e-mail: $\underline{\text { m.reiss @ucl.ac.uk }}$ 


\begin{abstract}
Connectedness to nature is a reflection of the human-nature relationship. Positive experiences and emotional connections to nature in childhood have been shown to increase the likelihood of positive attitudes towards the environment in adults. These, in turn, are an essential part of our ability to meet the challenges of the current environmental crisis.

In light of the importance of understanding and fostering the nature connectedness of children, our study sought to investigate this connection among students from an indigenous community, whose relationship with nature is influenced by a variety of cultural, social and environmental factors, not least of which is the fact that the environment in which they live is highly contaminated. We asked 294 fifth and sixth grade students (130 boys and 164 girls) who live in the Bedouin villages in Israel's Negev desert to complete an open questionnaire that had been specifically developed to elicit detailed information about these particular students' connection to nature.

Our analysis of the students' responses showed that students living in the Bedouin villages have ambivalent and complicated feelings about their connection to nature. Quantitative analyses showed that the students enjoy nature and spend a great deal of time outdoors, but that their awareness of their environment's contamination also leads them to avoid contact with natural spaces and fosters the sense that they lack the ability to take responsibility for their environment. A gender comparison showed some significant differences, with girls showing a greater nature enjoyment, empathy towards living creatures and sense of responsibility than boys, while boys mention more direct experiences in nature than girls. Qualitative analysis of the students' explanations showed that their nature connectedness was affected by a wide range of influences, including cultural and social factors (religious beliefs, traditionally distinctive gender roles, tribal territory and affiliation), and the various facets of their daily experience in a highly rural environment (weather conditions, playing in nature, instrumental views of nature).
\end{abstract}

Keywords: connectedness to nature $\bullet$ contaminated environment $\bullet$ indigenous $\bullet$ culture - gender 
الارتباط بالطبيعة هو انعكاس لعلاقة الإنسان بها. لقد تبين أن التجارب الإيجابية و الرو ابط العاطفية مع الطبيعة في

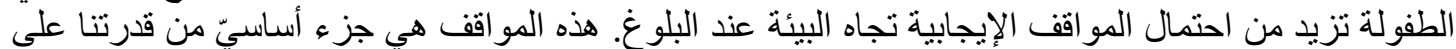
مو اجهة تحديات الأزمة البيئية الحالية.

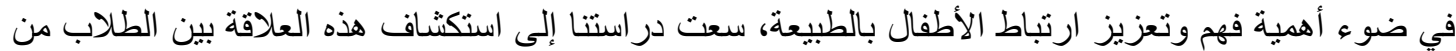

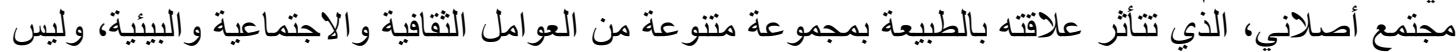

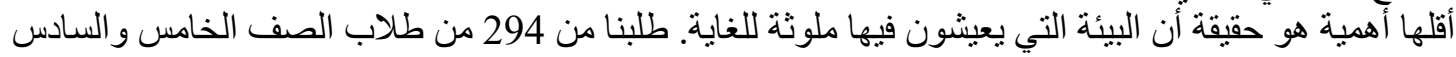

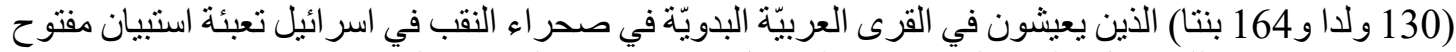

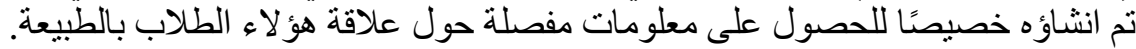

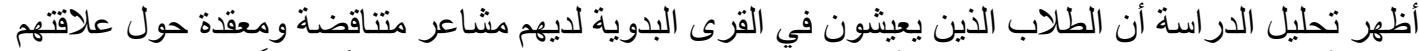

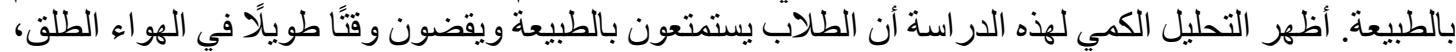

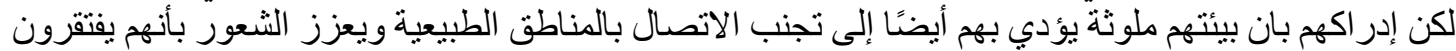

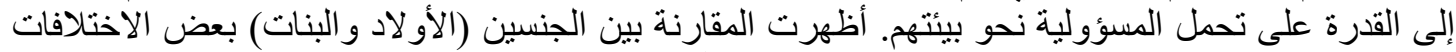

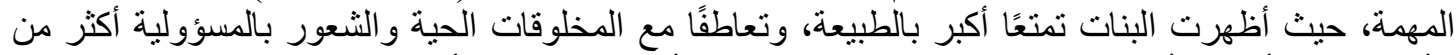

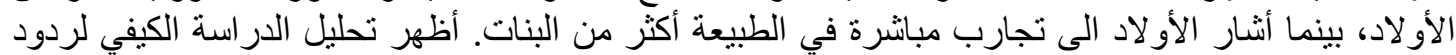

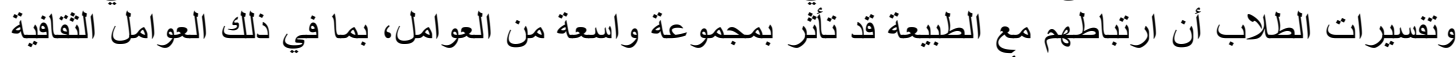

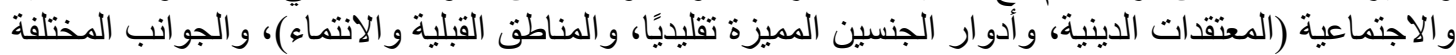
لتجربتهم اليومية في بيئة ريفية للغاية (الظروف المناخية النية، و اللعب في الطبيعة، ومفهوم النفعية للطبيعة). الكلمات المفتاحية: الارتباط بالطبيعة، البيئة الملوثة، المجتمعات الأصلانية، الحضارة، الجنس. 


\section{Indigenous children's connectedness to nature: the potential influence of culture, gender and exposure to a contaminated environment}

Connectedness to nature is an essential element in the human race's continued existence, since it reflects humanity's fundamental relationship with the natural world, whether it perceives itself as separate from that world or as an integral part of it (Lankenau 2018). Previous studies have shown that nature connectedness begins developing at a very young age, and that childhood is a critical time in the development of a relationship with the natural environment (Kals, Schumacher and Montada 1999). The experiences that individuals accumulate in nature during this time shape attitudes and values toward the environment that will follow them throughout their lives (Hinds and Sparks 2008) and profoundly influence their actions (Lankenau 2018).

Ethnic minorities, indigenous communities and communities from low socioeconomic backgrounds are all known to be at greater risk of frequent exposure to environmental pollutants (Adams and Savahl 2017). The living environments of such communities are often characterized by hazardous and contaminated natural spaces, which adversely affect the residents' wellbeing. In the past, indigenous communities typically lived in harmony with nature, and their connectedness to their natural environment was central to their culture and their way of life (Salmon 2000), but today this harmony and connectedness have been marred by the devastating impact of colonial urbanization and modernization (Abu-Saad 2008).

Despite the massive changes to their environments and lifestyles, there are significantly fewer studies devoted to connectedness to nature amongst indigenous populations, especially in the case of children. This gap has been maintained in spite of the recent rise in studies devoted to nature connectedness in children. In this context, Adams and Savahl (2017) noted:

... very few studies have asked children directly about what nature means to them and what it encompasses. At a foundational level, more research is required to promote better understandings as to how children in differing circumstances and SES communities construct nature, and what their perceptions of nature are before we can begin to ask them when, how, or why they engage in nature (p.316).

The few studies that have addressed the perceptions and nature connectedness of children have focused on describing educational experiences and activities in natural environments like lakes and streams (Liefländer, Fröhlich, Bogner and Schultz 2013), lagoons (Cheng and Monroe 2012) and botanical gardens (Ernst and Theimer 2011). These studies were constructed and designed from a Western perspective, with the primary purpose of fostering connections between Western children and natural environments. As a result, their results do not necessarily apply to other cases, particularly to the situations of children from different socio-economic or cultural backgrounds, such as children from indigenous communities.

The findings of such studies tend to focus primarily on their subjects' positive experiences in a healthy natural environment. To expand the meaning of the concept 'nature connectedness' beyond this context, we must learn more about people's perceptions and relationships toward natural spaces that are contaminated or unsafe (Kudryavstev et al. 2012). This is especially important in light of the fact that experiences in unsafe environments are no less powerful and significant than positive experiences in healthy environments, and no less influential in shaping individuals' relationships with their environments. 
The study presented here examines the nature connectedness of children living in unrecognized Bedouin villages in Israel's Negev desert. Its goal was to determine which aspects of nature connectedness are manifested by the children who live in these unrecognized Bedouin villages, and how their particular culture and environment impact their perspective and experience. The study focuses on these Bedouin children's direct day-to-day experiences in nature, and on the cultural activities that connect them to their environment. This is based on the assumption that both culture and experience in the physical environment can significantly affect nature connectedness (Blatt 2013), and that when we try to separate the physical characteristics of the environment from the socio-cultural ones, we lose our ability to understand the totality of the experiences and perceptions that make up a child's nature connectedness (Linzmayer and Halpenny 2014). Understanding the nature connectedness of indigenous communities, and acknowledging that it can diverge from Western experience and expectations in a variety of important ways, can help provide a sound basis for more effective, relevant environmental education, providing guidelines for developing new teaching programs tailored to the children's experiences and needs.

\section{What is nature connectedness?}

The study of nature connectedness is concerned with understanding the relationship between humans and their natural environment. In recent years, psychologicalecological research has produced a number of concepts with which to describe this relationship, and as a result, the term 'nature connectedness' does not have a single, clear and universal definition (see e.g. Beery 2013; Braun and Dierkes 2017). According to the research literature, this term covers various others used to describe aspects of the human-nature relationship, including emotional attachment to nature (Mayer and Frantz 2004), environmental identity (Clayton 2003), inclusion of nature in one's sense of self (Schultz 2002), sense of belonging to nature (Nisbet, Zelenski and Murphy 2009), and environmental sensitivity (Chawla 1998). Other references to the term 'nature connectedness' emphasize interactions and experiences in nature as the elements that foster the relationship between people and places. This perspective has brought about a renewed interest in the ability of specific experiences in specific places to change an individual's sense of connectedness to nature (Kudryavtsev et al. 2012).

Nature connectedness is an indication of the closeness between individuals and their natural environment, and it has been shown to be strongly connected to environmental concern and environmentally responsible behavior (Mayer and Frantz 2004). Connectedness to nature during childhood can significantly impact pro-environmental attitudes later in life, as indicated by retrospective studies in which adults identified childhood experiences in nature as a factor that encourages their engagement in environmental behavior (Chawla and Cushing 2007). Other studies, conducted amongst children, have shown similar trends, indicating that children's nature connectedness is fostered by the accumulation of time and experiences in nature. Initial contact between children and nature is generally based on time spent in natural environments near their homes (Cheng and Monroe 2012), and children's nature connectedness has been found to be strongly affected by the attitudes, values and behavior of their adult role models and families (Chawla and Cushing 2007).

\section{Nature connectedness and exposure to a contaminated environment}

According to Principle 1 of the 1992 Rio Declaration on Environment and Development, all human beings "are entitled to a healthy and productive life in harmony with nature" (United Nations 1992). Contact with nature carries many 
benefits, with positive implications for children's physiological, emotional, cognitive, social and spiritual well-being (see e.g. Kahn and Kellert 2002; Gill 2014). However, children from certain populations in the world do not currently have access to this basic right, because their nearby natural environment is contaminated and hazardous.

Today, contaminated environments tend to be concentrated in areas populated by socio-economically marginalized communities. The living spaces of such communities are often poor in quality, and characterized by perilous natural play spaces, fewer natural features, poorer services, more traffic and crime, and higher levels of physical deterioration than other, more affluent areas (Adams and Savahl 2015). As Tim Gill points out, spending time in the natural environment is "part of a 'balanced diet' of childhood experiences that promote children's healthy development, well-being and positive environmental attitudes and values" (Gill 2014, p.14). An inequality in access to healthy natural environments between children from differing ethnic and socioeconomic backgrounds therefore translates into a corresponding inequality in their development (Strife and Downey 2009).

Children from disadvantaged socio-economic backgrounds are often unable to fulfil their right to contact with a natural environment without exposing themselves to toxins. This problem is compounded by the fact that exposure to environmental toxins has been shown to impact children more profoundly than adults, since their immune systems are not yet fully developed (Strife and Downey 2009). As a result, exposure to a natural environment contaminated with toxins can cause these children more damage than not being exposed to it at all, while simultaneously denying them many of the advantages associated with a healthy natural environment.

Among the groups that have been most prominently affected by this environmental inequality are indigenous communities, like the Bedouins in Israel, Maoris in New Zealand, Aborigines in Australia and Zapatistas in Mexico (Abu Saad 2008; Amara, Abu-Saad and Yiftachel 2012). Many such communities suffer from political, legal and social discrimination, as well as isolation and neglect. Previously possessed of cultural, legal and territorial autonomy, these groups became subject to the external government of European settlers or Post-Colonial modern nation states, which stripped them of their rights and relegated them to the state's geographical, social and economic periphery (Cobo 1986).

These political processes have had a profound influence on indigenous communities' traditional ways of life. In addition to living under the laws of a culture that often differs radically from their own, the combination of social proximity and forced land appropriation has also pushed many indigenous people off lands that were central to their history, identity and economy, and into an expedited process of urbanization (Nasasra 2017). The dissonance between their traditional lifestyle and their new, urban one has been shown to generate radical disruptions in indigenous communities' existing social, cultural and economic systems (Holt 2006). Thus, far from improving their socioeconomic status, urbanization can often make matters worse (Abu-Saad 2008).

Despite the fact that the contamination of natural environments is a common phenomenon today, and the fact that underprivileged and indigenous communities are predominantly affected by it, there are relatively few studies devoted to nature connectedness in these populations. While there have been literature reviews devoted to the benefits of children's engagement with nature, and to describing their perceptions of nature as a space, most of the studies they describe were conducted in Europe and North America, focusing primarily on majority groups (Adams and Savahl 2017). These studies were also conducted in the context of urban environments, with 
participants from medium to high socio-economic backgrounds, from areas characterized by healthy and beautiful natural environments.

\section{Nature connectedness and culture}

Studies have found that the extent to which people feel connected to nature is significantly affected by cultural context (see e.g. Blatt 2013; Schulz 2002). Cultural factors have also been shown to shape people's fundamental beliefs about how nature works and how people interact with it (Milfont and Schultz 2016). Over the years, different cultural groups have developed different ideas, customs and characterizations regarding their relationship with nature, which reflect and influence their understanding and their models of the natural world.

Even amongst children, significant cultural differences have been found in perceptions and relationship towards nature, indicating that the culture in which children are raised shape their relation with the natural world (Chawla 2009). Studies comparing the environmental perceptions of children from indigenous communities with children from urban, Western backgrounds have shown them to be different. For example, studies comparing patterns of ecological thought between children from three communities - urban European-Americans, European-Americans living in rural areas and Menominee Native-American children - showed that the Menominee children tend to offer a less anthropocentric view than the European-American children (Medin et al. 2010). This finding was further supported by a study in 2012, which showed that Native-American children were more likely than European-American children to note elements like ecological relationships (between humans and other species), the utility of nature, psychological closeness to nature and emulation of non-human species (Unsworth et al. 2012).

The findings of these studies indicate that culture impacts individuals' perceptions and involvement in the natural world at an early age. Importantly, these studies compared groups of Menominee children not just to European-American children living in urban environments, but also to children from rural environments similar to their own. The fact that, despite the similarity of the children's environments, differences in perception were still found, emphasizes the importance of the children's cultural background. Ross et al. (2003) suggest that practices like traditional methods of fishing and gathering food may be what draws the Menominee children's attention to the relationship between humans and the various other species that live in their local environment.

Other cross-cultural studies, which have assessed environmental values (EV) and environmental behaviors (EB) in different cultural contexts, showed the impact of culture on children's environmental perceptions. Boeve-de Pauw and Van Petegem (2012) found significant differences in the ecological worldviews, especially in the dimension of human dominance, between children from indigenous communities in Zimbabwe and children from Belgium. Similarly, another study conducted by the same researchers, this time comparing children from Flanders, Guatemala and Vietnam, also showed that their EV and EB differed according to cultural context (Boeve-de Pauw and Van Petegem 2013).

Other studies have found that indigenous communities tend to have a holistic approach to nature that does not necessarily lend itself to the categories and definitions assumed by a Modern-Urban-Western perspective (see e.g. Lowan 2012; Aikenhead and Ogawa 2007). Arnon Ben-Israel, in his study of the Bedouin community in Israel, noted that the spatial perception of the Bedouins in their (only recently abandoned) 'nomadic phase' did not make more than the vaguest of distinctions between 'nature' 
and 'culture,' since the boundaries between these two spaces were not clearly defined (2009).

Another point that arises in studies of indigenous communities is that many of them are currently going through a process or urbanization and modernization as a result of colonial or post-colonial contact with Western societies (Abu-Saad 2008). The traditional lifestyle of indigenous communities is changing significantly under the influence of Western development, economy and technology, and as a result, some of their traditional environmental values are falling away (Holt 2006). Many indigenous communities are therefore in a state of transition, maintaining, or attempting to maintain, their traditional values, but also adopting many of the components of a Western lifestyle that is often at odds with their traditions.

Finally, one of the most powerful ways in which culture shapes children's relationships with nature is through gender roles. Atran and Medin's (2008) study of Mayan and Menominee Indian children, for instance, showed that the forest was a more authentic natural space for boys, since boys traditionally went to the woods with their fathers, and thus received a distinctly 'masculine' model of nature connectedness from them. In contrast, girls remained close to home with their mothers, so the natural spaces closer to home were more closely identified with them, and their nature connectedness was formed accordingly. Studies of Bedouin children reflect a similar spatial distinction in gender roles, with boys ranging farther afield, undertaking tasks such as herding sheep, while girls stay close to home with their mothers. One consequence of this is that women and children in the unrecognized Bedouin villages have higher rates of exposure to environmental toxins, like the smoke from backyard trash burning, than the men and older boys, whose work takes them farther from their village's immediate proximity (Meallem, Garb and Cwikel 2010).

\section{The purpose of the study}

The purpose of the study is to understand how the particular cultural, social and environmental factors that shape the lives of children in the unrecognized Bedouin villages of the Negev impact their connectedness to nature. To achieve this goal, the study focuses on the following questions:

1. How are the various aspects of nature connectedness expressed by these children?

2. How do the cultural, social and environmental characteristics of these children's lives reveal themselves in their descriptions of their relationship to nature?

\section{Study population}

The population for this study was composed of 294 fifth and sixth grade children (130 boys and 164 girls), who attend one of five different schools. In each school the children arrived from different unrecognized villages in Israel's Negev Desert.. The children are low academic achievers, and most of them come from low socio-economic backgrounds. It is important to note that these Bedouin children's lives are highly rural, so they have more access than most children to direct contact with nature. Their families also raise domestic animals like sheep, camels and chickens.

At the same time, the residents of these unrecognized villages are subject to continuous environmental and health hazards caused by contact with various factors in the settlements and their immediate surroundings (Sedawi et al. 2014). One major source of difficulty is the villages' lack of infrastructure (e.g., running water, sewer 
systems, waste disposal), due to their informal status. This problem is compounded by the fact that the community's traditional methods of waste disposal (incinerating it or leaving it to naturally decompose), while suitable to a nomadic past in which small groups of people generated waste that was primarily organic, are not well suited to their new, more sedentary lifestyle. The influence of modernization has led to the production of a great deal more inorganic waste that does not quickly biodegrade (Figure 1). Moreover, the lack of municipal disposal services has led the community to dispose of its waste by burning it themselves or dumping it in nearby streambeds - both practices that carry significant and continual health hazards.

Insert Figure 1 here

\section{Research tool}

Data for this study were gathered by means of an open questionnaire, which was specifically developed to provide information regarding these children's attitudes and connection to nature. The first part of the questionnaire consisted of 35 statements, some of which were taken from the literature on nature connectedness, and some of which were drawn from preliminary interviews conducted with ten Bedouin children for that purpose (for the full details regarding the questionnaire's development, see Sedawi et al. submitted). The questionnaire was designed to measure five aspects of connectedness to nature: nature enjoyment, empathy for living creatures, sense of oneness, sense of responsibility, and experience of nature in my immediate environment. While the first four aspects were taken from a previous tool, developed by Cheng and Monroe (2012) for measuring nature connectedness, the final aspect was added specifically to reflect the lives of these particular children. Each statement in the questionnaire was accompanied by an illustration that reflects its content, and the children were asked to mark agree/disagree under every statement to indicate that they agree/disagree. For a full list of the questionnaire's statements, their sources and which aspect they were designed to measure, see Appendix 1.

The questionnaire was administered at five different schools with the aid of three research assistants. The researcher introduced herself to the children and conducted a short, informal conversation with them to allow them to become familiar with her and with the research assistant. The children were then told that they would be asked to complete a questionnaire about nature attachment, and that the information in the questionnaire would be anonymous and confidential - they did not need to write their names.

While the children completed the questionnaire, the researcher read the statements aloud to avoid any problems with reading comprehension. The children were asked to note whether they agreed or disagreed with the statement, and not move on to the next one until it was read aloud.

Next, the children were asked to choose eight statements that they found interesting and would like to explain - four with which they agreed and four with which they disagreed. They were asked to write down the reasons that led them to agree or disagree with each statement. Because some of the children were reluctant to write, we told them that the research assistants would help them with the writing. The researcher and assistants approached the children who needed help; the children told them their responses and they wrote them down.

The children's explanations provided the qualitative data for the study. They helped us understand the children's reasons for choosing the statements that they had chosen 
to represent their opinions. Answers to the closed questionnaire alone would not have allowed us to understand the children's views in as much depth; the use of qualitative tools, like interviews and open questionnaires, can help fill in the missing information (Creswell and Tashakkori 2007). Completing the questionnaire took a total of two lessons (90 minutes).

\section{Ethics}

Participants were accessed via five elementary schools located in the participating community. Ethical clearance was obtained from the ethics committee of Kreitman School at Ben-Gurion University and the Chief Scientist of the Ministry of Education. Permission was obtained from the principal of each school prior to the research being conducted. With the assistance of the deputy principal and class teachers, letters were sent to the children's houses and consent forms were signed by one parent or guardian and sent back to the school.

\section{Data analysis}

Because our research tool combined quantitative and qualitative techniques, the data analysis consisted of a combination of statistical analysis and qualitative content analysis.

For statistical purposes we implemented descriptive statistics, using SPSS.

Differences between boys and girls were determined using: (a) the Chi-squared test to test differences at the level of the statement, and (b) the Wilcoxon rank sum test - to examine gender differences at the level of the aspects of connection to nature. The distribution of each of the five measures of nature connectedness was not normal (tested using A q-q plot graph and a Shapiro-Wilk test), and t-tests were therefore inappropriate.

To conduct the qualitative analysis, the children's explanations for their statements were coded and divided into categories (Strauss and Corbin 1990). The analysis process was inductive, with the categories being constructed 'bottom up' (from the specific to the general). In the first stage, open coding, each explanation was examined separately, so as not to impose any categories on the different explanations. The purpose of this stage was to establish preliminary categories that arise from the data.

It is important to note that at this stage we did not examine the children's explanations in relation to the nature attachment categories provided in the literature. This means that - despite the fact that these explanations were elicited from questionnaires in which each statement was meant to relate to a specific aspect of nature attachment- we collected all of the explanations together and categorized them by their content, rather than by the nature attachment aspect they were 'supposed' to reflect. For example, the statement 'When I am in nature I feel happy' belongs to the 'nature enjoyment' aspect of the questionnaire, but the children's explanations for their answers were not always related to enjoyment, but rather to their other experiences of nature. Some children, for instance, explained their answer by citing the usefulness of nature, e.g., "I like being in nature because it has plants and flowers, the sheep eat them ... without nature the sheep would die." Others reflected on its negative aspects, "I don't like nature because I fall on the thorns."

In the second stage of the qualitative data analysis, axial coding, connections and relationships were drawn between the categories to organize them into associated categories. In the third stage, selective coding, the data were gathered into ten central categories (as detailed in part two of the results section below). In the fourth and final stage, a conditional matrix (a theoretical explanation) was constructed for the 
categories. The data analysis was validated by five experts in the field (two advisors and three $\mathrm{PhD}$ students), who reviewed the categories until agreement was reached.

\title{
Results
}

This section is divided into two parts, according to the two research questions. Part one describes a quantitative analysis of the children's answers to the nature connectedness questionnaire, according to the questionnaire's five aspects (see Table 1). Part two provides a qualitative thematic analysis of how the cultural, social and environmental characteristics of these children's lives are expressed in their explanations of their answers to the questionnaire.

Part one - Five aspects of nature connectedness as expressed by the children

\author{
Insert Table 1 here
}

\section{1) Nature enjoyment}

This aspect focusses on affective characteristics, such as positive emotional experiences in nature. It can include both general enjoyment, and the specific enjoyment of particular components of nature (such as wildflowers, birdsong, cleanliness). The data show a relatively high level of enjoyment in nature on the children's part, with $89 \%$ agreeing that nature makes them feel happy, $67 \%$ enjoying plant life, and $84 \%$ enjoying the sound of birds. When we analyzed this aspect according to gender, we found that a higher percentage of girls than boys feel happy in the nature $(96 \%$ vs $81 \%, p<0.001)$. Moreover, $77 \%$ of the girls noted that they like seeing wild flowers, vs $55 \%$ of the boys, and $91 \%$ of the girls liked hearing birdsong, vs $74 \%$ of the boys. A comparison of the median scores for the aspect as a whole showed a significant difference $(\mathrm{U}=5619.5$, $\mathrm{Z}=7.29, \mathrm{p}<0.001)$ between girls $(\mathrm{Mdn}=5)$ and boys $(\mathrm{Mdn}=4)$ (see Table 2$)$.

Insert Table 2 here

\section{2) Experience of nature in my immediate environment}

This aspect focusses on the specific experiences of the Bedouin children in their immediate environment. The statements in this aspect were adopted after the interviews that we conducted with children to adapt the questionnaire to this particular study population. The Bedouin children's experiences in their immediate environment include encounters with natural elements like the pasture, the stream, the dunes, domesticated animals, and local weather conditions.

Analysis of this aspect shows that the children expressed less enjoyment towards direct, physical experiences in their immediate environment than they had when discussing nature more generally. One of the points at which the Bedouin children encounter nature is the pasture, but only $54 \%$ of them reported going to the pasture as a positive experience. Similarly, only $27 \%$ of the children reported enjoying playing in the stream, and only $50 \%$ enjoy playing in the sand.

A gender comparison of the children's references to their physical, concrete experiences of their immediate natural environment shows that a higher percentage of boys than girls described that experience as enjoyable and fun. For example, $48 \%$ of the boys said they like playing in the water, vs $10 \%$ of the girls $(p<0.001) ; 65 \%$ of the 
boys like playing in the sand, vs $38 \%$ of the girls, and $73 \%$ of the boys like going to the pasture vs $38 \%$ of the girls. The overall score for 'experience of nature in my immediate environment' (see Table 2) was found to be significantly higher ( $U=18254, \mathrm{Z}=-10.58$, $\mathrm{p}<0.001)$ amongst boys $(\mathrm{Mdn}=6.5)$ than amongst girls $(\mathrm{Mdn}=4)$.

\section{3) Empathy towards living creatures}

This is an affective aspect, which focusses on the children's ability to understand and identify with the feelings of others. In this case, it refers to the ability to share and understand the experiences of animals rather than humans. The data analysis shows an ambivalence in the children's empathy towards living creatures. On the one hand, 78\% of the children's noted feeling sad when wild animals are hurt, and $84 \%$ did not like seeing them living in a contaminated environment. On the other hand, over half of the children expressed feelings of disgust towards animals in nature, and noted that they like hunting pigeons.

A gender comparison of the children's answers showed that the girls expressed more empathy towards animals than the boys. It showed that $87 \%$ vs $67 \%$ reported feeling sad when wild animals are hurt, and that $89 \%$ vs $77 \%$ do not like to see wild animals living in a contaminated environment. The overall score in this aspect (Table 2) was found to be significantly $(U=6045.5, Z=6.53, p<0.001)$ higher amongst girls than amongst boys (Mdn=5 vs $M d n=4)$.

\section{4) Sense of oneness with nature}

This aspect addresses the relationship between people and nature, examining the children's perceptions toward humanity's place in nature. It focusses on whether the children believe themselves to be part of nature and feel a sense of equality with other, non-human creatures. Analysis of the data for this aspect showed that $71 \%$ of the children noted that they cannot live without plants, and $66 \%$ noted that they cannot live without animals. Gender comparison showed no differences (U=9349, $\mathrm{Z}=1.86$, $\mathrm{p}=0.063$ ) between boys and girls in oneness with nature.

\section{5) Sense of responsibility and concern for nature}

This aspect focusses on children's awareness of the importance of preserving nature, and their belief in taking responsibility for protecting, respecting and helping the natural environment. The children in the study revealed an ambivalent response to the 'sense of responsibility' aspect. On the one hand, $84 \%$ of them were willing to protect animals in their environment, and $66 \%$ were willing to preserve the environment around them. However, $60 \%$ of the children reported that they were not capable of helping the stream in their vicinity, and about half expressed a lack of responsibility for protecting flowers by reporting that they like to pick them.

Both boys and girls expressed ambivalence in their feelings of responsibility and concern for nature. Nevertheless, the girls' explanations showed greater concern for the importance of cleanliness and protecting the environment. A greater percentage of girls than boys $(83 \%$ vs $72 \%, \mathrm{p}<0.05)$ were also willing to tell their friends not to harm animals. Similarly, $72 \%$ of the girls vs $45 \%$ of the boys said they were willing to tell their friends not to throw trash on the ground. The overall score for this aspect (Table 2) was found to be significantly $(U=6532.5, Z=5.79, p<0.001)$ higher amongst girls than boys $(\mathrm{Mdn}=6$ vs $\mathrm{Mdn}=4)$.

Part two - Reflections of the cultural, social and environmental characteristics of the children's lives in their explanations 
Our thematic analysis of the children's explanations showed that their nature connectedness was influenced by a variety of cultural, social and environmental factors, the most prominent and pertinent of which are described below. Though information of this type does not lend itself to absolute distinctions, the ten factors on this list can, for convenience's sake, be broadly divided into two groups. Thus, while the first five can be said to be the more 'social' or 'historical' factors (i.e., factors rooted in the particular history and traditions of the Bedouin people), the second five are strongly 'situational,' in the sense that they reflect the various consequences of the fact that these children live directly in and off their natural environment.

\section{1) Beliefs}

This theme encompasses a range of cultural beliefs, including religious views, 'popular beliefs' and superstitions. First and foremost, the children's explanations showed that their perceptions of nature are influenced by their belief in the tenets of Islam. For example, they associated the importance of cleanliness with their religious beliefs in statements like, "I like to see nature clean, because the prophet said ... cleanliness comes from faith," and "I am willing to say something to a friend who litters, because cleanliness comes from faith and dirt comes from the demon." Religious belief was also one of the (multiple) factors that influenced their preference for rain over sun. As one child explained, "I like when it rains, because rain is a blessing from God."

The children's religious beliefs were also reflected in their explanations of their perceptions of and relationships towards animals. The children believe that good behavior towards animals is rewarded by God, while bad behavior is punished. This was reflected in multiple explanations, like, "God created animals, so hurting them is 'haram' (religiously forbidden)," "whoever harms animals will get sins and punishment from God," and "God rewards people who help animals."

In addition to beliefs explicitly associated with the children's religion, we also found evidence of superstitions and 'popular beliefs' amongst the children, which lead them to regard some species with animosity since they symbolize bad luck. For example, one child responded to a statement about seeing a dead bird with the answer, "it's dead, why should I be sad? The raven brings bad luck. You shouldn't feel sad. When you're running and you see a raven, you fall...owls too."

\section{2) Experiences with domestic animals}

The traditional lifestyle of the Bedouin community was (and to a large extent still is) based on animal husbandry, primarily raising and herding sheep. As a result, these Bedouin children are exposed to domesticated animals at home (like sheep, goats, horses, donkeys, camels, chickens and ducks). While the quantitative data analysis of this aspect showed that most of the children (70\%) enjoy riding animals, and 57\% like milking goats, qualitative analysis of the children's explanations revealed mixed feelings toward the domestic animals they encounter.

It is worth noting that these animals are in the vicinity of the children's homes at all times, and that the need to care for them seems to be an element in their ambivalence. On the one hand, the children see the animals they raise as part of the household, expressing affection toward them, and a fondness for petting and playing with them. One child explained, "I like animals, they sleep in our yard." Another said, "I like petting the goats, it gives me a nice, warm feeling."

On the other hand, the children expressed a variety of negative reactions to these animals. Some, for instance, expressed feelings of distance and disgust toward the domestic animals under their care. One child told us, "it's disgusting to catch the goats." 
Another said, "I don't like going to the pasture because the cows stink." The children also expressed feelings of fear towards these animals - such as the fear that they will fall off the animal or be attacked by it: "I don't like herding because the sheep butt you," "I don't like riding horses and donkeys because they kick," "I don't like riding. Animals can harm us and I might fall off if I ride them." Finally, some of the children's explanations revealed frustration and anger at the animals' behavior, e.g., "I don't like milking the goats because they move a lot, push the bucket and the milk spills," "the sheep run away and tire me out by the time I get them home."

\section{3) Traditionally distinctive gender roles}

The children's explanations reflected the influence of the distinctiveness of gender roles in Bedouin society. For example, the girls' explanations included more references to negative reactions like disgust and fear than the boys' did. This is likely related to the fact that the boys in Bedouin society spend more time out of the house than the girls do, and take greater responsibility for the task of herding. The gender difference was explicitly noted in one girl's explanation, in which she told us, "I don't like herding goats because that's boys' work."

Indeed, the boys' explanations more prominently referenced the experience of playing in their natural environment, reflecting the fact that they tend to have more freedom to move around outside than the girls do. The girls, who spend most of their time near their homes with their mothers, more often referred to the aesthetic contributions that natural elements like flowers can make to their immediate environment. The implied gender-role influence on such considerations was stated explicitly by one of the boys, who exclaimed, "flower smells are stinky. That's for girls. Boys aren't interested in flowers because that's nonsense for girls."

\section{4) Tribal territory and affiliation}

Bedouin society is divided into a series of tribes, each of which claims ownership and responsibility for specific territory. Some villages are populated by members of a single tribe, while others are composed of more than one, with different territories in the village belonging exclusively to different tribes. Moreover, each tribe is further subdivided into different extended families (i.e., a grandfather, his sons, their sons, and all of their wives and children). They are allocated territory of their own within the tribe's territory, which is then further subdivided into spaces for each smaller, paternal household. This is highly relevant to the children's perception of their environment because, as their explanations show, they see whatever lies outside their own affiliated group's territory (both in and around their village) as irrelevant, and therefore beyond their responsibility for its protection. This was reflected in multiple children's statements, where they made clear distinctions between their 'people' and other 'people,' as in 'I protect the environment around me and don't owe anything to the other people" and "I'm willing to clean only in our people's space; everyone should clean in their own people's area."

\section{5) Living in a natural environment that is contaminated}

The final 'social/historical' factor that impacts the children's perceptions and relationships with nature in various ways is the fact that the natural environment in which they live is currently contaminated. The villages in which these children live do not have regular waste disposal services and, as a result, a great deal of garbage accumulates in their vicinity. This situation is reflected in the feelings of revulsion that the children reported towards the natural landscape that surrounds them, describing it 
as dirty. For example, they said, "the pasture can be dirty sometimes and I don't like going there," and "I don't like playing in the water, because it's dirty and it stinks."

The children's responses also reflected a fear of dangers to their health due to the hazards of their natural environment. These fears lead them to avoid physical contact with certain places in their immediate environment. For example, "the water in the stream is dirty and causes sickness. The stream transmits germs," "I don't like playing in the sand because my hands will get dirty, and that will make me sick," and "I don't like playing on the dunes because my cousin played there and she found a piece of metal and was injured."

These children's explanations reflected the difficulties involved with living in their unrecognized settlements, which lead some of them to prefer living in a city, with its prospect of greater accessibility to things like shops and a more comfortable life. For example, "in the city the roads and the transportation are better than the dirt roads we have. They damage our cars," "because in the city there are shops and things." Another dominant difficulty raised by the children's explanations is the trash and dirt accumulating in their villages. One child explained, "the village is dirty. I don't like it dirty. I want a clean place to live in"; another said, "the city is big and beautiful, nicer than my village, orderly, organized and without garbage."

It is possible that the children's sense that their environment is dirty and disorganized may be a factor in the apathy and lack of commitment or responsibility towards the environment that some of them expressed, through statements like "I'm not the environment's servant," and "I'm too lazy to preserve the environment. It's tiring." This possibility is further supported by the feelings of helplessness some children reported in the face of the overwhelming waste and pollution problems faced by their community. This sense of hopelessness was expressed in a wide variety of statements, among them, "there are no trash cans to throw the garbage in," "people litter, I can't tell all the people not to litter," "the streambed is full of garbage. I can't clean up all the garbage," "because there's lots of garbage there; I'll clean it and then they will throw stuff again and the amount of garbage will grow," and "there's lots of garbage polluting the environment; we have to burn it, I know burning pollutes the air, but where can we put it? I hate seeing garbage thrown on the ground. Mother always asks me to clean."

\section{6) The natural environment as a playground}

One major factor that arises from the fact that these Bedouin children still live very much in a natural environment is their oft-voiced perception of nature as a place to play. Bedouin children play outside a great deal, and nature is part of their villages' immediate environment. It is also worth noting that their difficult socio-economic situation makes it difficult for these children's parents to buy them toys and games, which also contributes to the amount of time they spend playing outside. They play out in the pasture, on the dunes and by the stream. Qualitative analysis of their explanations revealed references to the time they spend playing in the natural environment: "I feel happy in nature, we play, climb trees and have competitions," "I like going to the pasture with the sheep to play in the weeds," and "it's fun to slide down the dunes, I bring a piece of plastic, sit on it and slide."

\section{7) Nature as a disgusting place}

Another interesting aspect of the fact that nature is a constant presence in these children's lives is their awareness not just of its positive, but of its negative attributes. The children expressed discomfort and distaste not just towards artificial contaminants due to pollution, but towards naturally occurring aspects of their environment as well. 
For example, "I hate playing in the sand ... there's animal poo there," "the sand is dirty; there are slugs in it," "I don't like picking flowers; they have yucky worms in them," and "I don't like seeing animals hurt ... I don't like them to die because they smell bad." The children's explanations indicate that they are repulsed by elements of their natural environment, primarily animal feces, invertebrates and dead animals (like the carcasses of dead sheep).

The children's explanations also referred to their concerns over the hazards posed by various elements in their natural environment. For example, "I don't like playing in the stream, because it can flood and it's dangerous ... people drown in it," "I don't like playing on the dunes ... I like playing at home because it's safer than the dunes and I won't fall," "I don't like touching wildflowers because they are poisonous and cause diseases," "I don't like plants; they have biting ants in them," and "the sand gets in my eyes and it hurts."

Finally, living day to day within a rural environment elicited references to aspects of nature that the children found annoying, tiring or inconvenient. For example, "I don't like the bird sounds... when I'm sleeping they wake me up and I can't fall asleep," "I don't like playing in the sand, it makes my clothes dirty," "I don't like the weeds. They have thorns and they catch on my pants," and "there are lots of weeds ... they're dense and it's hard to run through them."

\section{8) The immediacy and impact of weather conditions}

Another byproduct of the Bedouin children's highly rural life is that they must contend regularly with adverse weather conditions. The children expressed their lack of enjoyment of weather conditions in the desert, with $65 \%$ reporting that they are bothered by the summer heat, and $24 \%$ reporting being bothered by the rain. In this context, it is worth noting that the area in which they live is very hot, but sees relatively little rain. Some of the children noted that they dislike certain weather conditions because they prevent them from playing outside: "the heat bothers me and I can't play outside," "in the winter there's mud, I can't go to school with mud." Other students connected their displeasure with the weather to their fear that their health will be compromised by harsh weather conditions: "the high heat makes people tired," "the sun gives you sunstroke, it's hot and we'll get sick," "the sun and the heat cause nosebleeds."

9) Perceiving nature in terms of its usefulness

The direct, unmediated use of natural resources is an integral part of the Bedouins' traditional lifestyle. For many years, Bedouin communities were entirely dependent on their immediate surroundings for survival, and this dependence (though to a lesser extent) is still an active part of these children's lives. In this context, our analysis of their explanations indicated that their sense of oneness with nature arises primarily from nature's usefulness.

The children explained that they need plants, animals and nature in general because these provide them with things that they require for survival. These things include food, for themselves and their livestock, as well as oxygen, light and water. This was expressed in explanations like, "plants give us oxygen and we can't live without plants," "nature is part of life and it's the most important thing to people. It makes food and drink."

In addition to basic necessities, the children also noted that nature provides them with certain luxuries and other things that increase their wellbeing, such as flowers to decorate their homes and animals to raise as pets (e.g., "I put the flowers in the vase, and the house smells nice," "I like picking flowers and giving them to my mother as a 
present"). It is worth noting in this context that the homes of the children who live in the unrecognized Bedouin settlements are not connected to the national electric grid. Some of them use generators, and others use solar units to generate electricity. As a result, the children also see nature as a source of electricity: "the light gives us electricity and lets us play on the computer."

Finally, while our results did show that the children see animals as entitled to live freely and peacefully, half of them also noted that they hunt pigeons. Pigeon hunting is a Bedouin cultural norm - a common practice in these children's communities. This was expressed in one of the children's explanations: "I hunt pigeons so I'll have pigeons. All the kids have pigeons...I want to be like the other kids." This norm, however, is more than tradition or habit; it is driven by the children's direct use of their natural environment for their family's sustenance. The children raise pigeons in their homes, which they both eat and sell. This was reflected in statements like "I hunt pigeons and bring them to mother. She cooks them and we eat them," and "I hunt pigeons and raise them. When the eggs hatch, chicks come out and I sell them."

\section{0) Perceiving oneself as part of nature}

Qualitative analysis of the children's explanations indicated that the children's relationship with the animals in their natural environment is complex - composed of a variety of different emotions of varying intensities. Some of the children's explanations revealed feelings of empathy and identification with animals' feelings, for example, "I feel sad when a bird is sick, I remember when I was sick and suffering, it probably feels that way too." Another child said, "If you take the chicks, the mother bird is sad. I'm also afraid the chicks will die with me. I don't want them to die because they're pretty." A third said, "when you collect butterflies, they suffer." The children also indicated that they saw animals as entitled to live free, safe lives, making statements like, "animals have the right to live in a clean environment," "I don't like bothering butterflies, because they want to live in peace," and "the butterflies were born to fly, not for us to capture them."

On the other hand, the children's explanations also reflected the fact that living in nature and making direct use of natural resources can lead to a competitive relationship with animals, since the children see themselves as vying with the animals for shared resources. Some of the children, for example, see wild animals, like birds, as competitors for resources, consuming or destroying things that the children need. They therefore told us, for example, "I don't feel sad when the crow dies, because it eats our chickens' eggs." Moreover, living in such close proximity to nature has allowed these children to develop a more practical perspective on life in a natural environment. For example, onechild told us, "I'm used to it. If a bird died, I'd give it to the cat. Why feel sad?" Another said, "when birds die, I don't feel bad because that's the cycle of life."

\section{Discussion}

This study provided an opportunity to examine the relationships between children living in unrecognized Bedouin settlements in the Negev and their natural environment. We addressed these relationships in the context of the concept of 'nature connectedness,' asking specifically, (a) Which aspects of nature connectedness are expressed among Bedouin children who live in unrecognized villages? (b) How are cultural characteristics expressed in the experiences of nature that these children have? Overall, the relationships we found can be associated with four different aspects of nature connectedness, as detailed below.

1. Enjoyment of nature in my immediate environment 
The children's responses to the questionnaire suggested that their relationship with their natural environment was not one of simple enjoyment, but was rather more ambivalent and complicated. On the one hand, our analysis showed that most of the children perceive nature as a place in which to have fun and play. The children spend a great deal of time outdoors, enjoying the natural landscape and the soothing silence of their natural environment. In this, our study supports previous literature, which has shown that contact with nature is a source of positive, pleasant experiences and emotions (see e.g. Hinds and Sparks 2008; Mayer and Frantz 2004), and that children who have easy access to nature as a place to play develop stronger ties to their natural environment (see, e.g., Cheng and Monroe 2012; Collado, Staats and Corraliza 2013).

At the same time, however, the children in our study also expressed negative feelings toward various aspects of their direct contact with nature, noting their fear of several potential causes of illness or injury. These children's contact with nature includes exposure to the hazards of environmental pollution, and to the consequences of harsh weather, which can make it difficult for them to enjoy their time outside. Previous studies have also noted that immediate contact with nature can carry health hazards due to harsh environmental conditions (Elsana, Elbedour and Shalev 2014) and evoke a negative affective response, especially if the environment is contaminated (Adams and Savahl 2016).

Our findings clearly showed the influence of local pollution on children's negative experiences and attitudes towards nature. Similar findings were noted by Adams and Savahl $(2015$; 2016), who studied perceptions of nature amongst children in South Africa. Their results indicated that pollution impacted the children's subjective sense of wellbeing as well as their health, with many children feeling that it was safer for them to stay indoors than to venture into open spaces that are perceived as a threat. Their studies, like our own, suggest that an unsafe natural environment can prevent children from enjoying the time they spend in it, and that feelings of insecurity can significantly limit children's involvement with their natural environment. This point is important in light of the studies which claim that separating children from nature is harmful to their development and wellbeing (see, e.g., Gill 2014; Keller, 2005), since it shows that it is not just the quantity but also the quality of the nature they experience that must be taken into account.

Other studies have challenged the assumption that there is a clear and simple correlation between experiencing, enjoying and caring for nature by addressing not the quality of the nature, but the quality of the experience. As Collado et al. (2015) pointed out, when assessing the relationship between children's 'Frequency of Contact with Nature' (FCN) and their environmental attitudes and behaviors, it is also important to address the 'type' of their exposure to nature. They therefore compared three types of daily exposure to nature - non-work-related exposure in a city, as well as work and non-work related in a rural area. They found that the association between FCN and environmental behavior was strongest for urban children, with no direct association found in the non-work-related rural area, and a negative one in the work-related rural area. They posit that these results may indicate "a ceiling effect of frequency of contact with nature," suggesting that amongst children for whom spending time in nature is "a common activity," the positive effects FCN "may be attenuated by children's familiarity with their daily surroundings or overshadowed by other factors known to influence children's environmental behaviors" (p. 71). Collado et al.'s conclusions reflect our own findings regarding the effects of our children's highly rural daily lives, which we expand upon further below. 
Overall, we found that the girls in our study expressed greater enjoyment of nature than did the boys. One explanation for this is the greater emphasis on aesthetic considerations expressed by the girls in their explanations. This corresponds with the findings of other studies in this field, which have shown that girls tend to express greater enjoyment of and more aesthetic perceptions toward the beauty of nature than do boys (Pointon 2014).

We also found differences in how boys and girls in our study described their experiences in their immediate environment. Our results showed that boys reported a great many more outdoor experiences than did the girls. We presume that this difference is related to the greater mobility that generally characterizes the lives of Bedouin boys, who work and play farther afield while girls remain closer to their homes. This finding corresponds to those of studies of other indigenous communities, which also show such a gender-based difference in mobility (Atran and Medin 2008).

\section{Empathy towards living creatures}

Previous studies have shown that empathy plays an important role in people's attitudes and behaviors towards nature, and that it is a predictor of behavior designed to preserve and protect the environment (Tam 2013). The results presented here show that the relationship between the children and the creatures that live around them is complicated. On the one hand, the children did express empathy and sorrow towards wild animals that were harmed by living in the contaminated natural environment that surrounds the children's homes. Researchers have claimed that taking on the perspective of animals harmed by pollution influences individuals' altruistic motivation to take action to preserve the wellbeing of other living creatures (Schultz 2000). In addition to feelings of empathy, the children also expressed moral opinions, regarding animals' 'right' to live safely and freely in a natural environment, and the importance of not doing anything to infringe on that right. Some of their moral perceptions were influenced by their religious beliefs, since Islam has several basic rules regarding proper behavior toward animals. These rules include caring for animals and protecting them from bodily harm.

Nevertheless, the study also showed that the children had difficulty developing empathy towards some of the animals in their environment, and that this difficulty stemmed from their daily experiences with these animals. The data suggested several explanations for the children's apparent lack of empathy. First, these children live and play in a desert environment, where they come into contact with a variety of hazardous reptiles and insects. These circumstances lead the children to recognize animals as a potential threat. A study by Prokop et al. (2010) showed that African children who had come into greater contact with life-threateningly venomous spiders expressed a greater fear of spiders than did Slovakian children. A later study (Prokop and Fančovičová 2013) showed that feelings of fear and disgust arising from contact with particular animals have a negative impact on children's willingness to protect them.

Second, our study also showed that the Bedouin children's daily experience of living in a natural environment and making direct use of natural resources can lead to feelings of rivalry with other animals, arising from the fact that they are competing with those animals for the same resources. Some of the children see wild animals, like birds, as competitors that steal resources (e.g., seeds, eggs) that belong to them. This competitive interaction leads them to perceive these animals as directly hostile to their own interests. Similarly, Johnson-Pynn et al. (2004) found that many indigenous Africans perceive wild animals as scavengers and pests that destroy their crops. 
Another factor that may influence the children's empathy is the fact that their daily experience with the realities of life in a natural environment may have led them to develop a rather more practical perspective towards animal life and death than is generally found in children who live in more urban environments. Some of the children in our study reported seeing the death of an animal as a routine part of the cycle of life, noting, for instance, that if they came upon a dead bird they would not cry over the bird's tragic fate, but would simply feed it to their cat. The Bedouin children in our study also did not show empathy towards animals from which their society derives nutritional or economic value - such as pigeons. Hunting pigeons (for food or for sale) is a common practice in Bedouin society (see also the 'oneness with nature' section below).

Finally, in addition to their daily experience with animals in nature, the children's empathy was also influenced by their belief in the myths and superstitions common in their families and the wider community. Superstitions can have a negative effect on animal-human relationships (Prokop and Tunnicliffe 2008). Our results showed that the children's superstitions caused them to express hatred and fear for certain animals, based on the belief that such animals (e.g., crows) can bring bad luck. Prokop and Tunnicliffe (2008) also showed that negative attitudes toward animals can be influenced by cultural pressure. They found a correlation between belief in myths and negative attitudes toward spiders, showing that stronger belief in the myth corresponded to stronger negative attitudes.

Our findings showed that the girls in our study expressed greater empathy than did the boys. This corresponds to the findings of other studies, like that of Tam (2013), which suggest that this is a byproduct of the fact that girls and women are generally socialized to value and take care of other people's needs. As a result, women tend to "empathize with the natural world to a larger extent, and in turn exhibit more natureprotecting behavior" (p. 101).

\section{Sense of oneness with nature}

Many researchers have argued that indigenous communities tend to be defined by a strong sense of oneness with nature. Salmon (2000) called this perception a 'kincentric ecology,' in which indigenous communities see themselves and their natural environment as part of an extended ecological family with a shared origin.

Our study, however, showed that the children were ambivalent in their feelings of oneness with nature. On the one hand, they exhibited a sense of identification and oneness with nature that arose from the direct and visible reliance on natural resources (e.g., farming, herding) associated with the still traditional aspects of their lifestyle (Abu-Rabia 1994). At the same time, however, the Bedouin children also expressed a sense of dominance over their natural environment, and the belief that they have the right to use the natural resources around them to suit their own desires and needs. The instrumental view of nature expressed by these children has been noted in the children of other indigenous communities, like the Native American Menominee (Unsworth et al. 2012), and children from indigenous communities in Zimbabwe (Van Petegem and Blieck 2006) and Guatemala (Boeve-de Pauw and Van Petegem 2012). The latter two studies showed that the children in Zimbabwe and Guatemala combined their sense that nature was there to be used with strongly positive attitudes toward environmental behavior, indicating their belief in a balance between protecting the environment and using it to provide for human needs.

It is worth noting, however, that we found that approximately half of the children in our study would not choose to keep living where they do, in rural villages surrounded 
by nature. In citing their reasons, they often referred to their village's lack of accessibility and its pollution problems, which make living in their rural environment a source of frustration and prevent the children from achieving a sense of oneness with nature. These issues were broadly echoed by Adams and Savahl (2016), who found that pollution led children to prefer playing in the 'safe' natural environments provided by their schools, rather than in the spaces near their homes.

Our findings did not reveal any significant differences between boys and girls in a sense of oneness with nature. This is different from the findings of other studies in the literature, according to which women show a greater sense of oneness than men, who tend to have a more instrumental and anthropocentric view of nature (Bogner and Wiseman 2004). One explanation for this may be that in other studies these aspects reflect the respondents' general worldview, while the explanations of the children in our study focused on their daily experiences and cultural practices. In that context, the children of both genders explained that they are connected to nature because it provides them with what they need to survive.

\section{Feelings of concern and responsibility}

Historically, the traditions and habits of indigenous communities have contributed to the conservation of nature, to the maintenance of habitats and to the continuation of local species diversity (Kideghesho 2008). For hundreds of years, the Negev Bedouins maintained their natural environment, in part because nearly all of the waste they generated was organic and easily biodegradable. Today, however, Bedouin society has incorporated many modern, inorganic materials into daily life, and the contents of the waste it generates have changed accordingly (Meallem et al. 2010). This change, combined with the fact that the unrecognized villages do not have organized waste removal services, means that the population of these villages is subject to the constant environmental and health hazards associated with pollution. Our study, like others before it (e.g., Adams and Savahl 2016; Kahn and Friedman 1995) showed that children who live in contaminated areas are aware of the impact of that contamination. Olufemi, Mji and Mukhola (2016) showed that South African children who had been directly impacted by pollution in their environment were more likely to see pollution as a problem than children who had not been. A previous study conducted by us amongst the Negev Bedouins in Israel showed that their awareness of the impact of discarded trash on the environment and on public health focused primarily on their daily lives and personal experiences, so that children tended to be knowledgeable about the effects of pollutants to which they had been personally exposed, like shards of iron and glass from the piles of trash near their homes (Authors 2014). It is therefore possible that the personal experiences of these Bedouin children with the negative impact of pollution on their daily lives have made them more aware of environmental dangers, and more concerned about preventing them for their own wellbeing.

However, although the children in our study showed concern for the environment, which is considered a significant factor in the development of responsible environmental behavior (Chawla 1998), they also expressed a lack of interest in taking responsibility for their environment. The literature on nature connectedness claims that having direct experiences in nature is a fundamental part of appreciating and caring about nature, and that children who lack such experiences will not develop this appreciation and care (Mayer and Frantz 2012). However, the children in our study live in an environment severely lacking in infrastructure, and in the basic conditions necessary for comfort and safety. In this context, the children expressed feelings of helplessness, and an inability to take responsibility for their natural environment. Strife 
(2012) and Kollmuss and Agyeman (2002) claimed that feelings of helplessness can lead to indifference and a reluctance to be responsible for the environment. It is therefore likely that harsh economic, political and infrastructural conditions can be obstacles that prevent people from engaging in environmental behavior (Kollmuss and Agyeman 2002). The issue of poor infrastructure was also addressed in Adams and Savahl's study, which showed that African children (aged 13 and 14 and attending a school in a low-income area in the Western Cape Province of South Africa) believed that their municipal services were insufficient to keep their natural spaces clean, and that this belief led to a "repudiation of responsibility" and a "culture of inconsideration" towards nature, characterized by indifference and apathy towards their natural environment (2015, p.204).

In addition to feelings of helplessness, the children in our study also expressed a lack of ownership for the area of their village. In this context, it is important to remember that, based on the socio-spatial structure of the children's villages, they are very likely to perceive significant portions of their immediate environment as 'not theirs.' As we noted above, Bedouin society is organized in a series of groups and subgroups, each of which is allocated its own parcel of 'private' land (Manor-Rosner, Rofè and Abu-RabiaQueder 2013). As a result, the children's villages contain very few 'public spaces' that belong to everyone (other than the roads and a few "public and commercial buildings" like the mosque or the general store). The rest are private, and only accessible to members of the group to which they belong. The children noted that they do not take environmental responsibility for areas that are not part of their tribe or extended family's territory. This could be an obstacle to the children's willingness to engage in environmental behavior, since studies have shown that feelings of ownership and connection to a place cause people to be more caring and involved, increasing their commitment to protect their environment and support sustainable development (Raymond, Brown and Weber 2010).

Our results showed that girls have a greater tendency than boys to express feelings of responsibility and concern. This may be due to differences in cultural expectations from boys and girls. The girls often noted in their explanations that they help their mothers keep the area around their homes clean, while the several of the boys said that cleaning was a girl's job. Socialization, cultural expectations and social norms shape gender roles and influence boys' and girls' relationships with their natural environment (Chawla 2009).

Nevertheless, it is worth noting that there is no clear consensus in the research literature on this issue. Some studies have shown that girls display more proenvironmental attitudes and concern for the environment than do boys (see for instance, Pointon, 2014). Other studies have found that there were no significant gender differences in this context (Liefländer and Bogner 2014).

\section{Implications of the study}

This study provided us with a wealth of information about how our children's nature connectedness was influenced by their cultural background, and by their experiences in their natural environment. Such information can be used as guidelines for the development of place-based intervention programs. Place-based education emphasizes the fostering of connections with specific places through interactions with and experiences in nature (Gruenewald 2003). It encourages a focus on context-specific experiences in particular places as a means of encouraging positive changes in nature connectedness (Raymond, Brown and Weber 2010). In promoting the development of such place-based education, it is important to take note of the following three points: 
a) Our findings showed that the children's nature connectedness was strongly influenced by their concrete, local, physical experiences in their natural environment, and by the norms and practices that govern their everyday lives. It is therefore important to see these specific local factors as assets upon which to build authentic, place-based learning. Utilizing the children's local, everyday experiences will make their learning more meaningful and provide a solid foundation for their relationship with their natural environment.

b) Empathy is an important component in nature connectedness and the development of environmental concern (Tam 2013). The empathy exhibited by the children in our study was complex. On the one hand, our findings indicated factors that contribute to the development of empathy towards animals, such as religious tenets and identification with animals in distress. On the other hand, we also discovered several obstacles to the development of empathy, most particularly norms associated with the use of animals for food and cultural superstitions that vilify particular species. We believe that understanding the mechanisms that influence the development of empathy is essential to the development of place-based education programs. Obstacles must be discovered so they can be addressed or avoided, and mechanisms that can help promote empathy should be identified and put to use.

c) Finally, our study showed that children who live in a contaminated environment are aware of that contamination's impact on their wellbeing. Exposure to environmental pollution caused the children to avoid contact with natural spaces and fostered the sense that they lacked the ability to take responsibility for their environment and change the current situation. When addressing populations that are exposed to environmental pollution, place-based education must not shy away from discussions of environmental justice. On the contrary, they must give expression to the full range of the place's social, political, economic and environmental aspects.

We further recommend that place-based education initiatives should work hand in hand with reclamation programs for improving the conditions of populations living in contaminated environments. In the case of our own study population, for example, the area in which they live is about to undergo a massive, five-year reclamation project for the nearby stream and its surroundings, as well as a process for the regulation of local waste disposal. These processes may well have a positive impact on these children's attitudes toward their natural environment, and on their willingness to take action to preserve it.

\section{References}

Abu-Rabia, A. (1994). Negev Bedouin and livestock rearing. New York: Berg.

Abu-Saad, I. (2008). Spatial transformation and indigenous resistance: The urbanization of the Palestinian Bedouin in southern Israel. American Behavioral Scientist, 51(12), 1713-1754. https://doi.org/10.1177/0002764208318928

Adams, S., \& Savahl, S. (2015). Children's perceptions of the natural environment: a South African perspective. Children's Geographies, 13(2), 196-211. https://doi.org/10.1080/14733285.2013.829659

Adams, S., \& Savahl, S. (2016). Children's discourses of natural spaces: Considerations for children's subjective well-being. Child Indicators Research, 10(2), 423-446. 
Adams, S., \& Savahl, S. (2017). Nature as children's space: A systematic review. TheJournal of Environmental Education, 48(5), 291321.https://doi.org/10.1080/00958964.2017.1366160

Aikenhead, G. S., \& Ogawa, M. (2007). Indigenous knowledge and science revisited. Cultural Studies of Science Education, 2(3), 539-620. https://doi.org/10.1007/s11422-007-9067-8

Amara, A. and Miller, Z. 2012. Unsettling settlements: Law, land, and planning in the Naqab. In: Amara, A., Abu-Saad, I. and Yiftachel, O. (eds), Indigenous (In)Justice: Law and Human Rights for Bedouin Arabs in the Naqab. The Human Rights Program, Harvard Law School, Harvard University Press, 57-98.

Atran, S., \& Medin, D. (2008). The native mind and the cultural construction of nature. Cambridge, MA: MIT Press.

Beery, T. H. (2013). Nordic in nature: friluftsliv and environmental connectedness. Environmental Education Research, 19(1), 94-117. https://doi.org/10.1080/13504622.2012.688799

Ben-Israel, A. (2009). Bedouin formation of place: Space and landscape construction by urbanized pastoral-nomads (Doctoral dissertation, Doctoral Dissertation. BeerSheva: Department of Geography, Ben-Gurion University of the Negev) (in Hebrew).

Blatt, E. N. (2013). Exploring environmental identity and behavioral change in an Environmental Science course. Cultural Studies of Science Education, 8(2), 467488. https://doi.org/10.1007/s11422-012-9459-2

Boeve-de Pauw, J., \& Van Petegem, P. (2012). Cultural differences in the environmental worldview of children. International Electronic Journal of Environmental Education, 2(1), 1-11.

Boeve-de Pauw, J., \& Van Petegem, P. (2013). A cross-cultural study of environmental values and their effect on the environmental behavior of children. Environment and Behavior, 45(5), 551-583. https://doi.org/10.1177/0013916511429819

Bogner, F. X., \& Wiseman, M. (2004). Outdoor ecology education and pupils' environmental perception in preservation and utilization. Science Education International, 15(1), 27-48.

Braun, T., \& Dierkes, P. (2017). Connecting students to nature-how intensity of nature experience and student age influence the success of outdoor education programs. Environmental Education Research, 23(7), 937-949. https://doi.org/10.1080/13504622.2016.1214866

Brügger, A., Kaiser, F. G., \& Roczen, N. (2011). One for all? Connectedness to nature, inclusion of nature, environmental identity, and implicit association with nature. European Psychologist, 16(4), 324-333. https://doi.org/10.1027/10169040/a000032

Chawla, L. 1998. Significant life experiences revisited: A review of research on sources of environmental sensitivity. Environmental Education Research, 4, 369-382. https://doi.org/10.1080/00958969809599114

Chawla, L., \& Cushing, D. F. (2007). Education for strategic environmental behavior. Environmental Education Research, 13(4), 437-452. https://doi.org/10.1080/13504620701581539

Chawla, L. (2009). Growing up green: Becoming an agent of care for the natural world. The Journal of Developmental Processes, 4(1), 6-23.

Cheng, J. C. H., \& Monroe, M. C. (2012). Connection to nature: Children's affective attitude toward nature. Environment and Behavior, 44(1), 31-49. https://doi.org/10.1177/0013916510385082 
Clayton, L. W. (2003). Identity and the natural environment: The psychological significance of nature. Cambridge, MA: MIT Press.

Cobo, J.M. (1986). Study of the problem of discrimination against indigenous populations. (E/CN.4/Sub.2/1986). New York: United Nations.

Collado, S., Corraliza, J. A., Staats, H., \& Ruíz, M. (2015). Effect of frequency and mode of contact with nature on children's self-reported ecological behaviors. Journal of Environmental Psychology, 41, 65-73. https://doi.org/10.1016/j.jenvp.2014.11.001

Collado, S., Staats, H., \& Corraliza, J. A. (2013). Experiencing nature in children's summer camps: Affective, cognitive and behavioural consequences. Journal of Environmental Psychology, 33, 37-44. https://doi.org/10.1016/j.jenvp.2012.08.002

Creswell, J.W. \& Tashakkori, A. (2007). Editorial: Developing publishable mixed methods manuscripts. Journal of Mixed Methods Research, 1(2), 107-111. https://doi.org/10.1177/2345678906293042

Elsana, F., Elbedour, K., \& Shalev, H. (2014). Pediatricians' perspectives on the challenges of care for Bedouin children in Southern Israel. International Public Health Journal, 6(1), 17.

Ernst, J., \& Theimer, S. (2011). Evaluating the effects of environmental education programming on connectedness to nature. Environmental Education Research, 17(5), 577-598. https://doi.org/10.1080/13504622.2011.565119

Gill, T. (2014). The benefits of children's engagement with nature: A systematic literature review. Children, Youth and Environments, 24(2), 10-34. https//doi.org/ 10.7721/chilyoutenvi.24.2.0010

Gruenewald, D. A. (2003). The best of both worlds: A critical pedagogy of place. Educational Researcher, 32(4), 3-12. https://doi.org/10.3102/0013189X032004003

Hinds, J., \& Sparks, P. (2008). Engaging with the natural environment: The role of affective connection and identity. Journal of Environmental Psychology, 28(2), 109-120. https://doi.org/10.1016/j.jenvp.2007.11.001

Holt, F. L. (2006). The Catch-22 of conservation: Indigenous peoples, biologists, and cultural change. Human Ecology, 33(2), 199-215. https://doi.org/10.1007/s10745005-2432-X

Johnson-Pynn, J. S., Johnson, L. R., Kityo, R., \& Lugumya, D. (2014). Students and Scientists Connect with Nature in Uganda, East Africa. International Journal of Environmental and Science Education, 9(3), 311-327. https://doi.org/10.12973/ijese.2014.217a

Kahn, P. H., \& Friedman, B. (1995). Environmental views and values of children in an inner-city black community. Child Development, 66(5), 1403-1417. https://doi.org/10.1111/j.1467-8624.1995.tb00942.x

Kals, E., Schumacher, D., \& Montada, L. (1999). Emotional affinity toward nature as a motivational basis to protect nature. Environment and Behavior, 31(2), 178-202. https://doi.org/10.1177/00139169921972056

Kideghesho, J. R. (2008). Co-existence between the traditional societies and wildlife in western Serengeti, Tanzania: Its relevancy in contemporary wildlife conservation efforts. Biodiversity and Conservation, 17(8), 1861-1881. https://doi.org/10.1007/s10531-007-9306-z

Kollmuss, A., \& Agyeman, J. (2002). Mind the gap: why do people act environmentally and what are the barriers to pro-environmental behavior? Environmental Education Research, 8(3), 239-260. https://doi.org/10.1080/13504620220145401 
Kudryavtsev, A., Stedman, R. C., \& Krasny, M. E. (2012). Sense of place in environmental education. Environmental Education Research, 18(2), 229-250. https://doi.org/10.1080/13504622.2011.609615

Lankenau, G. R. (2018). Fostering connectedness to nature in higher education. Environmental Education Research, 24(2), 230-244. https://doi.org/10.1080/13504622.2016.1225674

Liefländer, A. K., Fröhlich, G., Bogner, F. X., \& Schultz, P. W. (2013). Promoting connectedness with nature through environmental education. Environmental Education Research, 19(3), 370-384. https://doi.org/10.1080/13504622.2012.697545

Linzmayer, C. D., \& Halpenny, E. A. (2014). 'I might know when I'm an adult': Making sense of children's relationships with nature. Children's Geographies, 12(4), 412-428. https://doi.org/10.1080/14733285.2013.821262.

Lowan, G. (2012). Expanding the conversation: Further explorations into indigenous environmental science education theory, research, and practice. Cultural Studies of Science Education, 7(1), 71-81. https://doi.org/10.1007/s11422-012-9379-1.

Manor-Rosner, Y., Rofè, Y., \& Abu-Rabia-Queder, S. (2013). The unrecognized Bedouin villages - internal spatial order as a basis for development. The State of the Educational System in the Bedouin Sector. Jerusalem, Israel: Ministry of Education. https://doi.org/10.1201/b15685-92.

Mayer, F. S., \& Frantz, C. M. (2004). The connectedness to nature scale: A measure of individuals' feeling in community with nature. Journal of Environmental Psychology, 24(4), 503-515. https://doi.org/10.1016/j.jenvp.2004.10.001.

Meallem, I., Garb, Y., \& Cwikel, J. (2010). Environmental hazards of waste disposal patterns - A multimethod study in an unrecognized Bedouin village in the Negev area of Israel. Archives of Environmental \& Occupational Health, 65(4), 230-237. https://doi.org/10.1080/19338244.2010.486426.

Medin, D., Waxman, S., Woodring, J., \& Washinawatok, K. (2010). Humancenteredness is not a universal feature of young children's reasoning: Culture and experience matter when reasoning about biological entities. Cognitive Development, 25(3), 197-207. https://doi.org/10.1016/j.cogdev.2010.02.001.

Milfont, T. L., \& Schultz, P. W. (2016). Culture and the natural environment. Current Opinion in Psychology, 8, 194-199. https://doi.org/10.1016/j.copsyc.2015.09.009.

Müller, M. M., Kals, E., \& Pansa, R. (2009). Adolescents' emotional affinity toward nature: A cross-societal study. Journal of Developmental Processes, 4(1), 59-69.

Nasasra, M. (2017). The Naqab Bedouins: A century of politics and resistance. New York: Columbia University Press.

Nisbet, E. K., Zelenski, J. M., \& Murphy, S. A. (2009). The nature relatedness scale: Linking individuals' connection with nature to environmental concern and behavior. Environment and Behavior, 41(5), 715-740. https://doi.org/10.1177/0013916508318748.

Prokop, P., \& Fančovičová, J. (2013). Does colour matter? The influence of animal warning coloration on human emotions and willingness to protect them. Animal Conservation, 16(4), 458-466. https://doi.org/10.1111/acv.12014.

Prokop, P., Tolarovičová, A., Camerik, A. M., \& Peterková, V. (2010). High school students' attitudes towards spiders: A cross-cultural comparison. International Journal of Science Education, 32(12), 1665-1688.

https://doi.org/10.1080/09500690903253908. 
Prokop, P., \& Tunnicliffe, S. D. (2008). "Disgusting" animals: Primary school children's attitudes and myths of bats and spiders. Eurasia Journal of Mathematics, Science \& Technology Education, 4(2), 87-97. https://doi.org/10.12973/ejmste/75309.

Olufemi, A. C., Mji, A., \& Mukhola, M. S. (2016). Assessment of secondary school students' awareness, knowledge and attitudes to environmental pollution issues in the mining regions of South Africa: Implications for instruction and learning. Environmental Education Research, 22(1), 43-61. https://doi.org/10.1080/13504622.2014.984162.

Raymond, C. M., Brown, G., \& Weber, D. (2010). The measurement of place attachment: Personal, community, and environmental connections. Journal of $\begin{array}{llll}\text { environmental } & \text { psychology, } & \text { 30(4), } & \text { 422-434. }\end{array}$ https://doi.org/10.1016/j.jenvp.2010.08.002.

Ross, N., Medin, D., Coley, J. D., \& Atran, S. (2003). Cultural and experiential differences in the development of folkbiological induction. Cognitive Development, 18(1), 25-47. https://doi.org/10.1016/S0885-2014(02)00142-9.

Salmón, E. (2000). Kincentric ecology: Indigenous perceptions of the human-nature relationship. Ecological Applications, 10(5), 1327-1332. https://doi.org/10.1890/1051-0761(2000)010[1327:KEIPOT]2.0.CO;2.

Schultz, P. W. (2000). Empathizing with nature: The effects of perspective taking on concern for environmental issues. Journal of Social Issues, 56, 391-406. https://doi.org/10.1111/0022-4537.00174.

Schultz, P. W. (2002). Inclusion with nature: The psychology of human-nature relations. In P. Schmuck \& W. P. Schultz (Eds.), Psychology of sustainable development (pp. 61-78). Springer, Boston, MA. https://doi.org/10.1007/978-14615-0995-0_4.Stets, J. E., \& Biga, C. F. (2003). Bringing identity theory into environmental sociology. Sociological Theory, 21(4), 398-423. https://doi.org/10.1046/j.1467-9558.2003.00196.x.

Sedawi, W., Ben Zvi Assaraf, O., \& Cwikel, J. (2014). Conceptualizations of wasterelated implications on health and welfare among elementary school students in the Negev's Bedouin Arab community. Cultural Studies of Science Education, 9(4), 935-976.

Sedawi, W., Ben Zvi Assaraf, O., \& Reiss, M. (submitted). Challenges in measuring "connectedness to nature" among indigenous children: Lessons from the Negev Bedouin.

Strauss, A., \& Corbin, J. M. (1990). Basics of qualitative research: Grounded theory procedures and techniques. New York: Sage.

Strife, S. J. (2012). Children's environmental concerns: Expressing ecophobia. The Journal of Environmental Education, 43(1), 37-54. https://doi.org/10.1080/00958964.2011.602131.

Sobel, D. (2004). Place-based education: Connecting classroom and community. Nature and Listening, 4, 1-7.

Strife, S., \& Downey, L. (2009). Childhood development and access to nature: A new direction for environmental inequality research. Organization \& Environment, 22(1), 99-122. https://doi.org/10.1177/1086026609333340 .

Tam, K. P. (2013). Concepts and measures related to connection to nature: Similarities and differences. Journal of Environmental Psychology, 34, 64-78. https://doi.org/10.1016/j.jenvp.2013.01.004. 
Thompson, C. W., Aspinall, P., \& Montarzino, A. (2008). The childhood factor: Adult visits to green places and the significance of childhood experience. Environment and Behavior, 40(1), 111-143. https://doi.org/10.1177/0013916507300119.

United Nations (1992) Agenda 21. New York, United Nations. Retrieved August 02, 2018 , from https://sustainabledevelopment.un.org/content/documents/Agenda21.pdf.

Unsworth, S. J., Levin, W., Bang, M., Washinawatok, K., Waxman, S. R., \& Medin, D. L. (2012). Cultural differences in children's ecological reasoning and psychological closeness to nature: Evidence from Menominee and European American children. Journal of Cognition and Culture, 12(1-2), 17-29. https://doi.org/10.1163/156853712X633901.

Van Petegem, P., \& Blieck, A. (2006). The environmental worldview of children: A cross-cultural perspective. Environmental Education Research, 12(5), 625-635. https://doi.org/10.1080/13504620601053662.

Yiftachel, O., Roded, B., \& Kedar, A. (2016). Between rights and denials: Bedouin indigeneity in the Negev/Naqab. Environment and Planning A, 48(11), 21292161. https://doi.org/10.1177/0308518X16653404. 
Table 1: Distribution of students' answers to the nature connectedness questionnaire.

\begin{tabular}{|c|c|c|c|c|}
\hline Statement & $\begin{array}{l}\% \quad \text { of } \\
\text { agreeme } \\
\text { nt (all) } \\
\mathrm{N}=294 \\
\end{array}$ & $\begin{array}{l}\% \\
\text { agreeme } \\
\text { nt (boys) } \\
\mathrm{N}=130 \\
\end{array}$ & $\begin{array}{l}\% \\
\text { agreeme } \\
\text { nt (girls) } \\
\mathrm{N}=164 \\
\end{array}$ & p-value \\
\hline \multicolumn{5}{|l|}{ Nature enjoyment } \\
\hline When I'm in nature I feel happy. & 0.89 & 0.81 & 0.96 & $\chi^{2}(1)=17.02, p<0.001$ \\
\hline I like to see wild flowers in nature. & 0.67 & 0.55 & 0.77 & $\chi^{2}(1)=16.15, p<0.001$ \\
\hline There's nothing to see in nature. It's dirty. & 0.09 & 0.11 & 0.09 & $\chi^{2}(1)=0.20, p>0.05$ \\
\hline I like hearing the sounds of the birds in nature. & 0.84 & 0.74 & 0.91 & $\chi^{2}(1)=15.21, p<0.001$ \\
\hline I like seeing nature clean. & 0.94 & 0.87 & 0.99 & $\chi^{2}(1)=14.96, p<0.001$ \\
\hline I enjoy touching animals. & 0.69 & 0.83 & 0.57 & $\chi^{2}(1)=21.19, \mathrm{p}<0.001$ \\
\hline \multicolumn{5}{|l|}{$\begin{array}{l}\text { Experience of nature in my immediate } \\
\text { environment }\end{array}$} \\
\hline I like to play in the water of the stream. & 0.27 & 0.48 & 0.10 & $\chi^{2}(1)=49.53, p<0.001$ \\
\hline I have fun playing in the sand. & 0.50 & 0.65 & 0.38 & $\chi^{2}(1)=18.87, p<0.001$ \\
\hline I like going to the pasture. & 0.54 & 0.73 & 0.38 & $\chi^{2}(1)=33.67, p<0.001$ \\
\hline I like running and sliding on the dunes. & 0.64 & 0.83 & 0.49 & $\chi^{2}(1)=34.39, p<0.001$ \\
\hline The heat in summer really bothers me. & 0.65 & 0.52 & 0.75 & $\chi^{2}(1)=16.45, p<0.001$ \\
\hline The rain bothers me and makes it hard to walk. & 0.24 & 0.20 & 0.28 & $\chi^{2}(1)=2.12, p>0.05$ \\
\hline I like milking the goats. & 0.57 & 0.80 & 0.40 & $\chi^{2}(1)=46.70, p<0.001$ \\
\hline I like riding animals (donkey, horse, camel). & 0.70 & 0.92 & 0.53 & $\chi^{2}(1)=51.78, p<0.001$ \\
\hline The animal droppings in nature bother me. & 0.62 & 0.46 & 0.74 & $\chi^{2}(1)=22.24, p<0.001$ \\
\hline \multicolumn{5}{|l|}{ Empathy towards living creatures } \\
\hline I like collecting butterflies. & 0.37 & 0.36 & 0.38 & $\chi^{2}(1)=0.029, p>0.05$ \\
\hline I like gathering eggs and chicks. & 0.42 & 0.58 & 0.29 & $\chi^{2}(1)=25.26, p<0.001$ \\
\hline Sometimes I'm disgusted by animals in nature. & 0.53 & 0.44 & 0.61 & $\chi^{2}(1)=7.876, p<0.01$ \\
\hline I like feeding birds. & 0.88 & 0.79 & 0.95 & $\chi^{2}(1)=14.37, p<0.001$ \\
\hline $\begin{array}{l}\text { I don't like seeing wild animals living in a } \\
\text { contaminated environment. }\end{array}$ & 0.84 & 0.77 & 0.89 & $\chi^{2}(1)=6.91, p<0.01$ \\
\hline I like hunting pigeons. & 0.46 & 0.74 & 0.24 & $\chi^{2}(1)=69.37, p<0.001$ \\
\hline I feel sad when wild animals are hurt. & 0.78 & 0.67 & 0.87 & $\chi^{2}(1)=16.33, p<0.001$ \\
\hline \multicolumn{5}{|l|}{ Sense of oneness with nature } \\
\hline There are no animals in nature that interest me. & 0.16 & 0.25 & 0.08 & $\chi^{2}(1)=13.01, \mathrm{p}<0.001$ \\
\hline I can't live without plants. & 0.71 & 0.60 & 0.79 & $\chi^{2}(1)=12.10, p<0.001$ \\
\hline I can't live without animals. & 0.66 & 0.70 & 0.63 & $\chi^{2}(1)=1.28, p>0.05$ \\
\hline $\begin{array}{l}\text { I feel that I am more important than the plants } \\
\text { and animals. }\end{array}$ & 0.41 & 0.49 & 0.35 & $\chi^{2}(1)=5.69, p<0.05$ \\
\hline I prefer to live in the city. & 0.47 & 0.42 & 0.51 & $\chi^{2}(1)=2.35, p>0.05$ \\
\hline \multicolumn{5}{|l|}{$\begin{array}{l}\text { Sense of responsibility and concern for } \\
\text { nature }\end{array}$} \\
\hline I like picking wild flowers. & 0.70 & 0.58 & 0.80 & $\chi^{2}(1)=15.98, p<0.001$ \\
\hline $\begin{array}{l}\text { I'm willing to protect animals in my } \\
\text { environment. }\end{array}$ & 0.84 & 0.83 & 0.85 & $\chi^{2}(1)=0.141, p>0.05$ \\
\hline
\end{tabular}




\begin{tabular}{|l|l|l|l|l|}
\hline $\begin{array}{l}\text { I don't care if other children run over the } \\
\text { plants. }\end{array}$ & 0.25 & 0.38 & 0.15 & $\chi^{2}(1)=18.23, \mathrm{p}<0.001$ \\
\hline $\begin{array}{l}\text { I'm willing to say something to a friend who } \\
\text { hurts animals. }\end{array}$ & 0.78 & 0.72 & 0.83 & $\chi^{2}(1)=4.198, \mathrm{p}<0.05$ \\
\hline I'm willing to protect the nature around me. & 0.66 & 0.46 & 0.81 & $\chi^{2}(1)=37.73, \mathrm{p}<0.001$ \\
\hline $\begin{array}{l}\text { When I see a pile of garbage burning I think } \\
\text { that's good because the garbage is not } \\
\text { scattered around. }\end{array}$ & 0.38 & 0.51 & 0.29 & $\chi^{2}(1)=14.06, \mathrm{p}<0.001$ \\
\hline I can't help the stream in my environment. & 0.60 & 0.68 & 0.53 & $\chi^{2}(1)=6.543, \mathrm{p}<0.05$ \\
\hline $\begin{array}{l}\text { I'm willing to say something to a friend who } \\
\text { throws garbage on the ground. }\end{array}$ & 0.60 & 0.45 & 0.72 & $\chi^{2}(1)=21.43, \mathrm{p}<0.001$ \\
\hline
\end{tabular}


Table 2: Comparison between girls and boys at the level of the aspect as a whole

\begin{tabular}{|r|l|l|l|l|}
\hline $\begin{array}{c}\text { Connection to nature } \\
\text { aspects }\end{array}$ & $\begin{array}{l}\text { Boys } \\
\text { (median) }\end{array}$ & $\begin{array}{l}\text { Girls } \\
\text { (median) }\end{array}$ & $\begin{array}{l}\text { p-value } \\
(\mathbf{p})\end{array}$ & Effect size (r) \\
\hline Nature enjoyment & 4 & 5 & $<0.001$ & 0.37 \\
\hline $\begin{array}{r}\text { Experience of nature in my } \\
\text { immediate environment }\end{array}$ & 6.5 & 4 & $<0.001$ & 0.62 \\
\hline $\begin{array}{r}\text { Empathy towards living } \\
\text { creatures }\end{array}$ & 4 & 5 & $<0.001$ & 0.38 \\
\hline Sense of oneness with nature & 3 & 4 & 0.063 & 0.11 \\
\hline $\begin{array}{r}\text { Sense of responsibility and } \\
\text { concern for nature }\end{array}$ & 4 & 6 & $<0.001$ & 0.34 \\
\hline
\end{tabular}




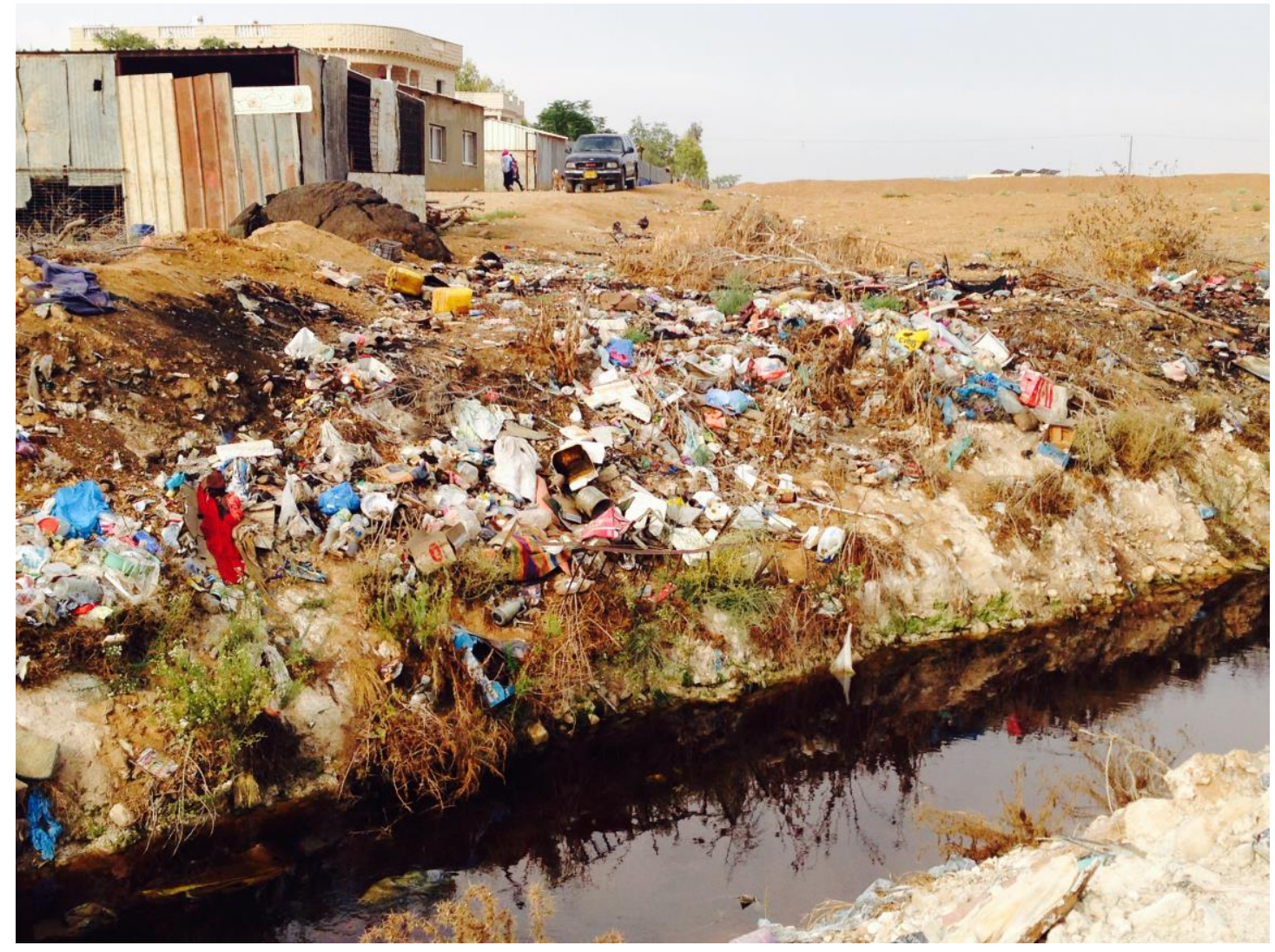

Figure 1: Waste accumulation in an unrecognized village. 
Appendix 1: The Connection to Nature Questionnaire

\begin{tabular}{|c|c|c|}
\hline $\begin{array}{l}\text { Aspect of } \\
\text { Nature } \\
\text { Connectedness }\end{array}$ & Statements & Source \\
\hline \multirow{6}{*}{$\begin{array}{l}\text { Nature } \\
\text { enjoyment }\end{array}$} & When I'm in nature I feel happy. & Cheng \& Monroe (2012) \\
\hline & I like to see wild plants. & Cheng \& Monroe (2012) \\
\hline & $\begin{array}{l}\text { There's nothing to see in the nature around } \\
\text { me. It's just dirty. * }\end{array}$ & Suggested by experts in the field \\
\hline & I like hearing the sound of the birds in nature. & Suggested by experts in the field \\
\hline & I like touching plants and animals. & Cheng \& Monroe (2012) \\
\hline & I like seeing nature clean. & Student interviews \\
\hline \multirow{9}{*}{$\begin{array}{l}\text { Experience of } \\
\text { nature in my } \\
\text { near } \\
\text { environment }\end{array}$} & I like to play in the water of the stream. & Student interviews \\
\hline & I have fun playing in the sand. & Student interviews \\
\hline & I like going to the pasture. & Student interviews \\
\hline & I like running and sliding on the dunes. & Student interviews \\
\hline & The heat in summer bothers me a lot. $*$ & Student interviews \\
\hline & $\begin{array}{l}\text { The rain bothers me and makes it difficult to } \\
\text { walk. * }\end{array}$ & Student interviews \\
\hline & I like to milk the goats. & Student interviews \\
\hline & $\begin{array}{l}\text { I like to ride on animals (donkey, horse, } \\
\text { camel). }\end{array}$ & Student interviews \\
\hline & In nature, animal droppings bother me. ${ }^{*}$ & Student interviews \\
\hline \multirow{7}{*}{$\begin{array}{l}\text { Empathy for } \\
\text { living } \\
\text { creatures }\end{array}$} & I like collecting butterflies. $*$ & Student interviews \\
\hline & I like collecting eggs and chicks. $*$ & Student interviews \\
\hline & $\begin{array}{l}\text { Sometimes I find animals in nature } \\
\text { disgusting. * }\end{array}$ & Suggested by experts in the field \\
\hline & I like to feed the birds. & Student interviews \\
\hline & $\begin{array}{l}\text { I don't like seeing wild animals living in an } \\
\text { unclean environment. }\end{array}$ & Suggested by experts in the field \\
\hline & I like hunting pigeons. & Student interviews \\
\hline & I feel sad when wild animals are hurt. & Cheng \& Monroe (2012) \\
\hline \multirow[t]{5}{*}{$\begin{array}{l}\text { Sense of } \\
\text { oneness }\end{array}$} & $\begin{array}{l}\text { There are no animals in nature that interest } \\
\text { me. } *\end{array}$ & Suggested by experts in the field. \\
\hline & I can't live without plants. & Cheng \& Monroe (2012). \\
\hline & I can't live without animals. & Cheng \& Monroe (2012). \\
\hline & $\begin{array}{l}\text { I feel that I am more important than the plants } \\
\text { and the birds. * }\end{array}$ & Similar to Mayer \& Frantz (2004) \\
\hline & I would prefer to live in the city. $*$ & Similar to Brügger et al. (2011) \\
\hline \multirow{7}{*}{$\begin{array}{l}\text { Sense of } \\
\text { responsibility }\end{array}$} & I like to pick wildflowers. $*$ & Student interviews \\
\hline & $\begin{array}{l}\text { I am willing to protect the animals in my } \\
\text { environment. }\end{array}$ & Suggested by experts in the field \\
\hline & $\begin{array}{l}\text { I don't care if other children run over the } \\
\text { plants. * }\end{array}$ & Suggested by experts in the field \\
\hline & $\begin{array}{l}\text { I am willing to say something to a friend who } \\
\text { harms an animal. }\end{array}$ & Suggested by experts in the field \\
\hline & I am willing to protect the nature around me. & $\begin{array}{l}\text { Similar to Müller, Kals \& Pansa } \\
\text { (2009) }\end{array}$ \\
\hline & $\begin{array}{l}\text { When I see a pile of burning trash, I think } \\
\text { that's good, because the trash is not scattered } \\
\text { around }\end{array}$ & $\begin{array}{l}\text { Similar to Müller, Kals \& Pansa } \\
\text { (2009) }\end{array}$ \\
\hline & I can't help the stream in my environment. * & Suggested by experts in the field \\
\hline
\end{tabular}


I am willing to say something to a friend who Suggested by experts in the field throws trash on the ground.

* Reverse statement 